\title{
Open
}

Review

\section{Understanding and targeting cancer stem cells: therapeutic implications and challenges}

\author{
Ke CHEN ${ }^{1}$, Ying-hui HUANG ${ }^{2}$, Ji-long CHEN $^{1,3, *}$ \\ ${ }^{1}$ CAS Key Laboratory of Pathogenic Microbiology and Immunology, Institute of Microbiology, Chinese Academy of Sciences (CAS), \\ Beijing 100101, China; ${ }^{2}$ China-Japan Union Hospital of Jilin University, Changchun 130033, China; ${ }^{3}$ College of Animal Science, \\ Fujian Agriculture and Forestry University, Fuzhou 350002, China
}

Cancer stem cells (CSCs) have been identified as rare cell populations in many cancers, including leukemia and solid tumors. Accumulating evidence has suggested that CSCs are capable of self-renewal and differentiation into various types of cancer cells. Aberrant regulation of gene expression and some signaling pathways has been observed in CSCs compared to other tumor cells. CSCs are thought to be responsible for cancer initiation, progression, metastasis, recurrence and drug resistance. The CSC hypothesis has recently attracted much attention due to the potential for discovery and development of CSC-related therapies and the identification of key molecules involved in controlling the unique properties of CSC populations. Over the past several years, a tremendous amount of effort has been invested in the development of new drugs, such as nanomedicines, that can take advantage of the "Achilles' heel" of CSCs by targeting cell-surface molecular markers or various signaling pathways. Novel compounds and therapeutic strategies that selectively target CSCs have been identified, some of which have been evaluated in preclinical and clinical studies. In this article, we review new findings related to the investigation of the CSC hypothesis, and discuss the crucial pathways involved in regulating the development of CSC populations and the advances in studies of drug resistance. In addition, we review new CSC-targeted therapeutic strategies aiming to eradicate malignancies.

Keywords: cancer; stem cell; leukemia; biomarker; ATP-binding cassette transporter; signaling pathway; tumor microenvironment

Acta Pharmacologica Sinica (2013) 34: 732-740; doi: 10.1038/aps.2013.27; published online 20 May 2013

\section{Introduction}

What are cancer stem cells (CSCs)? Recent studies have suggested that CSCs are immortal tumor-initiating cells that can self-renew and have pluripotent capacity ${ }^{[1]}$. CSCs have been identified in multiple malignancies, including leukemia and various solid cancers. Due to their extraordinary characteristics, CSCs are thought to be the basis for tumor initiation, development, metastasis and recurrence. In 1963, Bruce et al observed that only $1 \%-4 \%$ of lymphoma cells (not all cancer cells) can form colonies in vitro or initiate carcinoma in mouse spleen $^{[2]}$. However, the first compelling evidence proving the existence of CSCs is generally acknowledged to have been provided by Bonnet and Dick in $1997^{[3]}$. In their reports, only the $\mathrm{CD}^{+} 4^{+} \mathrm{CD} 38^{-}$cells from acute myeloid leukemia (AML) patients could initiate hematopoietic malignancy in NOD/ SCID mice. Importantly, this cell population possessed the ability to self-renew, proliferate and differentiate ${ }^{[3]}$. The first

\footnotetext{
* To whom correspondence should be addressed.

E-mail chenjl@im.ac.cn

Received 2013-01-16 Accepted 2013-03-06
}

report of CSCs in solid cancer came in 2003 from Al-Hajj, who demonstrated the presence of CSCs in breast cancer ${ }^{[4]}$. To date, CSCs have been discovered in a broad spectrum of solid tumors, including lung cancer ${ }^{[5]}$, colon cancer ${ }^{[6]}$, prostate cancer $^{[7]}$, ovarian cancer ${ }^{[8]}$, brain cancer ${ }^{[9]}$, and melanoma ${ }^{[10]}$, among others.

\section{The controversial cancer stem cell models}

Most tumors are thought to arise from one single cell that develops into a heterogeneous population. However, two distinct models have been proposed to account for tumor growth and the heterogeneity within tumors. In the cancer stem cell model, the modalities of cancer, such as initiation, progression, metastasis and recurrence, depend primarily on rare stem cells. The heterogeneity and hierarchy between all of the cells within a tumor result from asymmetric division of CSCs. This model suggests that tumors are highly hierarchical with a unique self-renewing population of cells at the top of the hierarchy. All other cells comprising the tumor bulk are derived from differentiated CSCs ${ }^{[11]}$.

However, an alternative view also exists, called the clonal 
evolution model (CE model) ${ }^{[12]}$. This model posits that all tumor cells contribute to tumor maintenance with differing capacities. The intercellular variation is primarily attributed to subclonal differences that result from genetic and/or epigenetic changes during cancer development.

Generally speaking, the CSC model emphasizes the concept of functional heterogeneity without considering the existence of intracellular genetic variation or genetically diverse subclones. In contrast, the CE model focuses on genetic heterogeneity but ignores the functional variation within individual genetic subclones.

Although these two models seem to be mutually exclusive ${ }^{[13]}$, accumulating evidence has suggested that neither the CSC model nor the CE model should be rejected. Recently, several groups have combined functional assays with genetic analysis to examine the genetic diversity of tumor propagating cells or tumor initiating cells in both leukemia and solid cancer $^{[14-16]}$. Anderson and co-workers first directly proved the existence of genetic diversity of cancer propagating cells within individual ETV6-RUNX1-positive acute lymphoblastic leukemia (ALL) patients ${ }^{[14]}$. In addition, the genetic diversity and relative dominance of subclones vary with the development of disease ${ }^{[14]}$. Similarly, Notta et al have established that individual $\mathrm{Bcr}-\mathrm{Abl}^{+}$ALL samples are composed of genetically distinct subclones that are related by a complex evolutionary process $^{[15]}$. These authors also determined that genetically diverse subclones already possess variably aggressive properties at the time of diagnosis ${ }^{[15]}$.

These studies have indicated that cancer stem cells exist but might evolve over time. An ancestral clone gives rise to at least two clonal lineages that evolve independently, with each clone acquiring diverse genetic aberrations; one clone emerges as the dominant diagnostic clone, while the other clone gives rise to the predominant clone containing additional mutations at relapse ${ }^{[15]}$.

\section{Characteristics of cancer stem cells}

CSCs are distinct populations of tumor cells. CSCs have multiple unique features that cause them to be vital for tumor formation. CSCs can self-renew ${ }^{[17]}$ and are immortal and necessary to maintain the population of tumor cells. CSCs are pluripotent and can generate tumor cells with different phenotypes, which results in the growth of the primary tumor and emergence of new tumors.

\section{CSC biomarkers}

Due to the close relationship between CSCs and tumor initiation, progression, metastasis and drug resistance, the isolation of these cells from the total cancer cell population is essential for detailed studies. Distinct and specific surface biomarker phenotypes can be used to distinguish CSCs from other tumor cells and normal stem cells. Currently, the most common method used to identify CSCs is fluorescence-activated cell sorting (FACS) based on cell surface markers or intracellular molecules.

The leukemia stem cell (LSC), which specifically displays a CD $34^{+} \mathrm{CD} 38^{-}$surface marker phenotype, was the first studied and best understood type of $\mathrm{CSC}^{[3]}$. The loss of CD38 distinguishes LSCs from normal hematopoietic stem cells (HSCs), although both LSCs and HSCs are CD34 ${ }^{+[3]}$. Subsequently, more selective surface markers of LSCs have been discovered, and combinations of these markers have been used. For example, the combination of $\mathrm{CD} 34^{+} \mathrm{CD} 38^{-} \mathrm{HLA}-\mathrm{DR}^{-} \mathrm{CD} 71^{-} \mathrm{CD} 90^{-}$ $\mathrm{CD} 117^{-} \mathrm{CD} 123^{+}$is uniquely present on the surface of LSCs but not on normal HSCs ${ }^{[18]}$.

Regarding solid cancers, Al-Hajj et al have identified $\mathrm{ESA}^{+} \mathrm{CD} 44^{+} \mathrm{CD} 24^{-} /{ }^{\text {low }}$ Lineage ${ }^{-}$cells as breast cancer stem cells. The authors found that compared to other cell populations, this population has a greater capacity for tumor formation in NOD/SCID mice ${ }^{[4]}$. In addition, Singh et al have found that transplantation of a very small number of $\mathrm{CD}_{133}{ }^{+}$brain cancer cells can generate tumors in NOD/SCID mice, suggesting that CD133 might be an important CSC marker ${ }^{[19]}$.

Although great progress has been made in understanding CSC surface molecules, many issues still remain to be addressed. Here, we summarize partial phenotypes of CSC markers according to the cancer types (Table 1). However, we must realize that CSC markers are still not perfect; not all CSCs express the markers, and some non-CSC cancer cells may also express the markers. For this reason, the markers

Table 1. Cell surface phenotypes of CSCs.

\begin{tabular}{|c|c|c|}
\hline Tumor type & Phenotype of CSCs markers & Reference \\
\hline Leukemia & $\mathrm{CD} 34^{+} \mathrm{CD} 38^{-}{ }^{-H L A-D R}-\mathrm{CD}^{-} 1^{-} \mathrm{CD}^{-} 0^{-} \mathrm{CD} 117^{-} \mathrm{CD} 123^{+}$ & [18] \\
\hline Breast cancer & $\mathrm{ESA}^{+} \mathrm{CD} 44^{+} \mathrm{CD} 24^{-/ \text {low }}$ Lineage $^{-}, \mathrm{ALDH}_{-} \mathbf{1}^{\text {high }}$ & {$[4,20]$} \\
\hline Liver cancer & $\mathrm{CD}_{133^{+}}, \mathrm{CD}_{49 \mathrm{f}^{+}}, \mathrm{CD}^{+} \mathrm{O}^{+}$ & {$[21,22]$} \\
\hline Brain cancer & $\mathrm{CD}_{133^{+}}, \mathrm{BCRP}^{+}, \mathrm{A}^{2} \mathrm{~B}^{+}, \mathrm{SSEA}^{-}{ }^{+}$ & {$[19,23]$} \\
\hline Lung cancer & $\mathrm{CD} 133^{+}, \mathrm{ABCG} 2^{\text {high }}$ & {$[24,25]$} \\
\hline Colon cancer & $\mathrm{CD}_{133^{+}}, \mathrm{CD}_{4} 4^{+}, \mathrm{CD}_{166}{ }^{+}, \mathrm{EpCAM}^{+}, \mathrm{CD}_{2} 4^{+}$ & [26-28] \\
\hline Multiple myeloma & CD138- & {$[29,30]$} \\
\hline Prostate cancer & $\mathrm{CD}_{4} 4^{+}, \alpha 2 \beta 1^{\text {high }}, \mathrm{CD}_{13} 33^{+}$ & [7] \\
\hline Pancreatic & $\mathrm{CD}_{133^{+}}, \mathrm{CD}_{4} 4^{+}, \mathrm{EpCAM}^{+}, \mathrm{CD}_{2} 4^{+}$ & {$[31,32]$} \\
\hline Melanoma & $\mathrm{CD} 2 \mathrm{O}^{+}$ & [10] \\
\hline Head and neck cancer & $\mathrm{CD}_{4} 4^{+}$ & [33] \\
\hline
\end{tabular}


can be used to identify CSC-rich subpopulations but might not be able to unambiguously isolate all of the CSCs.

\section{ATP-binding cassette}

ATP-binding cassette $(A B C)$ transporters are membrane transporters that can pump various distinct and structurally unrelated small molecules (such as cytotoxic drugs and dyes) out of cells at the expense of ATP hydrolysis. Normal stem cells and cancer stem cells appear to express high levels of $\mathrm{ABC}$ transporters. This phenomenon could contribute to multidrug resistance (MDR) because many anti-tumor drugs can be pumped out, thereby resulting in low intracellular drug concentrations ${ }^{[25,30,34]}$. Thus, the elevated levels of $A B C$ transporters enable cancer stem cells to resist current cancer therapies ${ }^{[25,35]}$. The well-known "shining stars" of the ABC superfamily include multidrug resistance proteins (MRPs/ $\mathrm{ABCC})$, breast cancer resistance protein (BCRP/ABCG2) and P-glycoprotein (P-gp/ABCB1) $)^{[35]}$. High expression levels of $\mathrm{ABC}$ transporters in malignant stem cells can be determined by treatment of cells with Hoechst 33342 dye. Rare cells containing high levels of the $\mathrm{ABC}$ transporters expulse Hoechst; this fraction is designated as side population (SP) cells ${ }^{[35]}$. Accumulated data have shown that numerous cell lines and tumors contain SP cells and that this cell population possesses a greater capacity for tumorigenesis than non-SP cells.

\section{Key signaling pathways}

Dysregulation of signaling pathway networks plays an important role in enabling CSCs to retain stem cell properties. As shown in Figure 1, the pathways and elements that are involved in the control of self-renewal and differentiation of cancer stem cells and normal stem cells include PI3K/

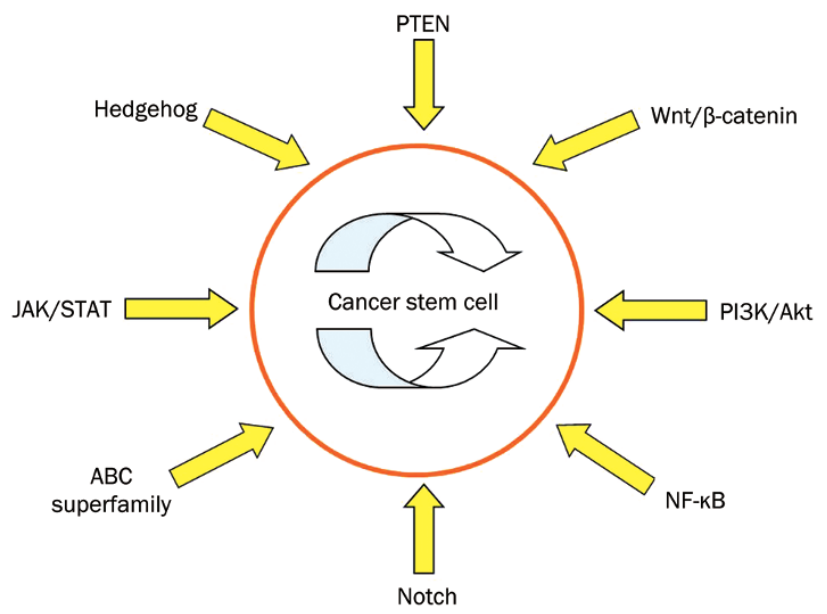

Figure 1. Signal pathways related with cancer stem cells. Dysregulation of signal pathway network plays an important role in retaining the stemness of CSCs. Pathways and elements involved in the control of selfrenewing and differentiation of cancer stem cells as well as normal stem cells include PI3K/Akt, JAK/STAT, Wnt/ $\beta$-catenin, hedgehog, Notch, NF$\kappa B, A B C$ superfamily and so on. Depending on these aberrant pathways, cancer stem cells acquire its unique ability to initiate carcinoma and promote recurrence after surgery.
Akt, PTEN ${ }^{[36]}$, JAK/STAT, Wnt/ $\beta$-catenin, hedgehog, Notch, NF-KB, Bcl-2, and others ${ }^{[37-43]}$.

The PI3K/AKT signaling pathway is involved in numerous cancers, including acute myeloid leukemia (AML) and chronic myeloid leukemia (CML). AKT activation is very important for cellular transformation and tumorigenesis. We have observed the role of AKT1 containing an E17K mutation in $\mathrm{v}$-Abl-mediated cellular transformation ${ }^{[38]}$. The AKT1 (E17K) mutant can cause increases in the protein levels of Bcl-2 and the phosphorylation of the pro-apoptotic protein $\mathrm{BAD}$, resulting in enhanced resistance to apoptosis. In addition, other members of the PI3K pathway (such as PTEN and mTOR) also function in the maintenance of LSCs. Silencing or defective mutations of PTEN have been observed in various cancers, including T-cell acute lymphoblastic leukemia, prostate cancer, melanoma, glioblastoma and endometrial carcinoma ${ }^{[44]}$.

The JAK/STAT signaling pathway is also involved in tumor initiation. Aberrations in the JAK/STAT pathway have been recognized in many cancers, especially leukemia. $\mathrm{V}$-Abl is a strong non-receptor tyrosine kinase that can induce the malignant transformation of pre-B cells by affecting the JAK/STAT pathway. Pim-1 and Pim-2 kinases have been shown to be induced by v-Abl-dependent JAK/STAT signaling in pre-B cells and play important roles in cellular transformation ${ }^{[45]}$. In addition, the JAK2-V617F mutation has been shown to be a critical factor that contributes to the malignant transformation of hematopoietic cells ${ }^{[46]}$. An important mechanism for negative regulation of the JAK/STAT signaling pathway is mediated by members of the suppressor of cytokine signaling (SOCS) family. Because activation of JAK/STAT signaling is required for transformation by several oncogenes, overcoming the regulatory effects of SOCS- 1 and SOCS-3 has been proposed to be necessary for tumor formation. Indeed, signaling activated by Bcr-Abl, a tyrosine kinase that causes $\mathrm{CML}$, has been shown to lead to tyrosine phosphorylation of SOCS-1 and SOCS-3, thereby impairing the ability of these proteins to inhibit JAK/STAT signaling pathway activation ${ }^{[47]}$.

Nuclear factor kappa B (NF-kB), a transcription factor that regulates the expression of multiple genes, participates in numerous cellular responses to stimuli such as cytokines, microbial antigens, free radicals and ultraviolet irradiation ${ }^{[39]}$. An increasing body of evidence has shown that NF-kB affects the expression of several apoptosis-related proteins, such as Bcl-xL, Bcl-2, survivin, cellular inhibitors of apoptosis (cIAPs), TRAF and cell cycle regulatory components. Aberrant NF-kB activation causes cancer development and progression, chemoresistance, chronic inflammation and autoimmune diseases $^{[48,49]}$.

The well-known Notch, Hedgehog and Wnt signaling pathways play fundamental roles in maintaining CSC populations. Notch signaling affects self-renewal and lineage-specific differentiation of normal human breast stem cells ${ }^{[50]}$. Moreover, Notch4 activity is elevated in breast CSCs, and inhibiting Notch 4 activity can reduce the breast CSC population, thereby suppressing tumor initiation ${ }^{[42]}$.

Aberrant regulation of the Hedgehog pathway is associated 
with numerous human malignancies and is a critical factor affecting the outcome of treating the disease ${ }^{[51]}$. Several agents targeting the Hedgehog pathway have shown promising preclinical results and are currently under investigation in phase I and II clinical trials ${ }^{[51]}$.

The maintenance of CSC stem cell properties has been shown to be associated with the Wnt signaling pathway. Abnormal Wnt/ $\beta$-catenin signaling has been identified in various malignancies, such as leukemia, colon, epidermal, breast and cutaneous carcinoma ${ }^{[52,53]}$. Human colon carcinoma, one of the best studied tumors, is caused by defective mutations in the adenomatous polyposis coli (APC) gene ${ }^{[54]}$. Defective mutations in APC result in the inappropriate stabilization of $\beta$-catenin, thus activating the Wnt cascade and inducing epithelial cell transformation ${ }^{[54]}$.

\section{Therapies targeting cancer stem cells}

Current therapeutic strategies against cancer have severe limitations that frequently lead to treatment failure. A common cause of treatment failure in multiple malignancies is resistance to chemotherapy and radiotherapy. In addition, many strategies that are not sufficiently selective against CSCs can be toxic to healthy tissues, and patients usually face the risk of recurrence and metastasis because most therapies cannot eliminate $\mathrm{CSCs}^{[55]}$. Accumulated evidence has established that CSC populations are more resistant to conventional cancer therapies than non-CSC populations. Therefore, the elimination of CSCs is crucial in treating malignant diseases ${ }^{[56-58]}$.

Recently, multiple novel therapeutic systems have been designed with the aim of killing CSCs and altering the microenvironment (niches) supporting these cells. Both subtle surface marker differences and alterations in signaling pathways are alluring therapeutic targets. Scientists have identified multiple potential CSC therapeutic targets, including the $A B C$ superfamily, anti-apoptotic factors, detoxifying enzymes, DNA repair enzymes and distinct oncogenic cascades (such as the Wnt/ $\beta$-catenin, hedgehog, EGFR and Notch pathways ${ }^{[58,59]}$. Currently, some therapeutic strategies can successfully kill CSCs, while others are still under preclinical and clinical evaluation. A summary of new CSC-targeted therapeutic strategies is shown in Figure 2.

\section{Targeting cellular surface markers}

Researchers often choose ligands or antibodies against tumor surface makers to enhance the specificity of therapeutic strategies. Important interest has been generated in the development of monoclonal antibodies to target CSCs. For example, CD33 is highly expressed in most AML cells. Thus, gemtuzumab ozogamicin, a humanized anti-CD33 mouse monoclonal antibody conjugated to the cytotoxic agent calicheamicin, has been developed and widely used to treat $\mathrm{AML}^{[60]}$.

Markers differentially expressed between normal stem cells and CSCs, including CD44 ${ }^{[61]}, \mathrm{IL}_{-} 3 \mathrm{R}^{[62]}$, and the immunoglobulin mucin TIM-3 $3^{[63]}$, have been utilized to specifically target leukemia stem cells in human AML. In each case, treatment with antibodies against these cell surface molecules dramati-

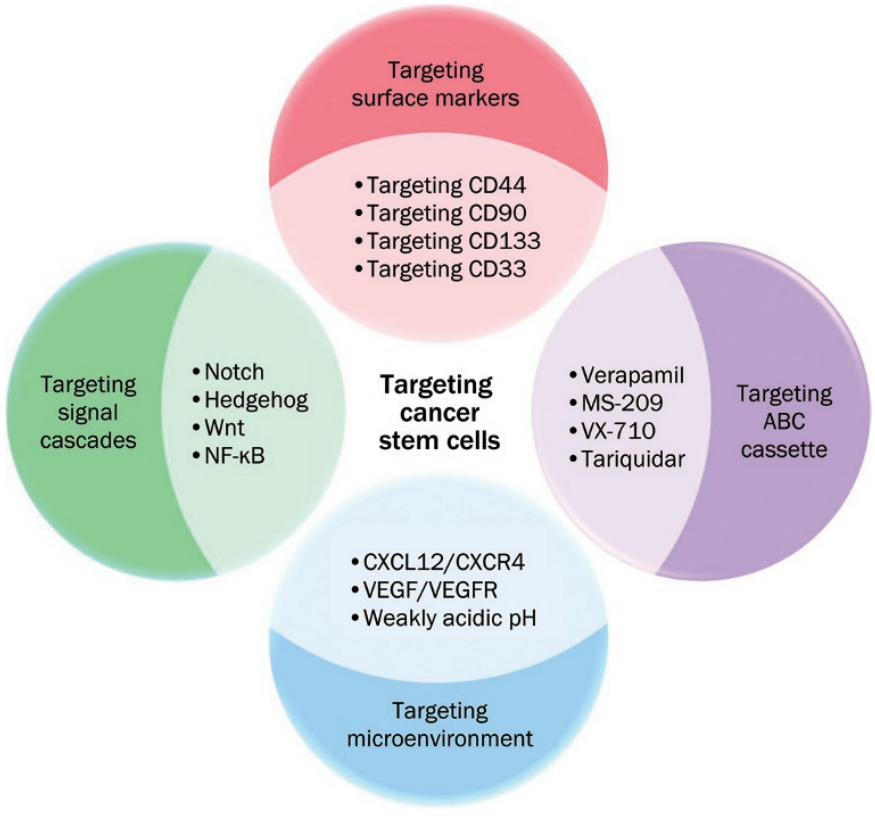

Figure 2. Therapies targeting cancer stem cells. Numerous therapies aiming at eradicating cancer stem cells have been developed during these years. Four different areas could recapitulate the current popular ideas mostly. By selectively targeting surface markers of CSCs (red area), more accurate and less side effects could be achieved. With the help of modern molecular biology techniques, more and more crucial signal elements and pathways have been unearthed (green area). By intervening aberrant pathways, specific characteristics of CSCs are suppressed and promising outcome has been reported. Molecular drugs inhibiting $A B C$ cassette (purple area) have reached the third generation (tariquidar) and some of them are undergoing clinical trials. In addition, tumor microenvironment nursing CSCs also draws much attention (blue area). Either cutting off the growth of blood vessel or exploiting the special PH environment, has showed alluring prospects.

cally decreases leukemogenicity and eradicates CSCs in mice. Antibodies against CD47, which is expressed at much higher levels in ALL than in normal cells, may also effectively kill leukemia stem cells ${ }^{[64]}$. In treating MCF-7 breast cancer, an anti-CD44 antibody-conjugated gold nanorod has been used to target and photo-ablate CD44 ${ }^{+}$cells, which display significant cancer stem cell characteristics. Using this approach, targeted cells absorb near infrared light, which results in increased local temperature at the designated location ${ }^{[65]}$.

An anti-CD90 antibody has also been reported to protect bone marrow-derived multipotent stromal cells from differentiation into chondro-, osteogenic, or adipo-lineages ${ }^{[6]}$. In addition, CD133 is highly expressed in many types of CSCs, including lung cancer, breast cancer, and glioma. Patients with high levels of CD133 show poor clinical outcomes ${ }^{[67]}$. For example, increased CD133 mRNA expression correlates with a high risk of death in colon, prostate and head and neck cancer ${ }^{[68]}$. Thus, therapy against CD133 might represent a promising strategy for cancer treatment. CD133 ${ }^{+}$cells in glioblastoma (GBM) display cancer stem cell-like properties ${ }^{[69]}$. Interestingly, a recent study has shown that treatment with carbon nanotubes con- 
jugated to an anti-CD133 monoclonal antibody followed by irradiation with near infrared laser light can selectively target CD133 ${ }^{+}$GBM cells, and the photothermolysis caused by the nanotubes can kill the targeted cells ${ }^{[69]}$. In addition, disruption of CD133 expression by short hairpin RNA in human glioblastoma neurospheres has been shown to impair the self-renewal and tumorigenic capacity of the neurosphere cells ${ }^{[70]}$.

\section{Targeting ATP-driven efflux transporters}

Antitumor drug efflux caused by ATP-driven pumps is the primary reason for chemoresistance ${ }^{[55,71,72]}$. Investigators have designed numerous methods to evade, neutralize or even exploit drug efflux pumps to overcome drug resistance. Several pharmacological agents that can interact with $\mathrm{ABC}$ transporters have been developed to inhibit multidrug resistance $(\mathrm{MDR})^{[73,74]}$.

The first P-gp efflux pump inhibitor to be identified was verapamil, which is often used in SP analysis to block the exclusion of Hoechst dye ${ }^{[75]}$. Simultaneous treatment with verapamil and antitumor drugs, such as Dox, paclitaxel or vincristine, has displayed promising therapeutic effects.

Khdair et al have delivered methylene blue (a type of P-gp inhibitor) and Dox simultaneously into BALB/c mice bearing syngeneic JC adenocarcinoma tumors. Markedly increased accumulation of drugs within the lesion, enhanced tumor cell apoptosis, suppressed cancer cell proliferation, impaired tumor growth and significantly improved animal survival were observed ${ }^{[76]}$.

Some investigations have identified a number of novel $A B C$ transporter inhibitors that suppress both P-gp and MRP1, such as MS-209, VX-710, and tariquidar ${ }^{[73,77,78]}$. Recent trials with MS-209 have shown promising results in overcoming drug resistance in breast cancer ${ }^{[77]}$ and other solid cancers (ClinicalTrials.gov Identifier: NCT00004886). Tariquidar is another inspiring inhibitor. The combination of tariquidar and docetaxel is under investigation (sponsored by the National Cancer Institute) for the treatment of recurrent or metastatic ovarian, cervical, lung and kidney malignancies (ClinicalTrials.gov identifier: NCT00072202). Similarly, the combination of tariquidar with Dox, etoposide, mitotane and vincristine is being tested in patients with primary, recurrent, and metastatic adrenocortical cancer (Clinical-Trials.gov identifier: NCT00073996 ${ }^{[73]}$.

An alternative strategy targeting $A B C$ transporters involves regulating the protein expression levels of these transporters. Sims-Mourtada et al have indicated that Hedgehog signaling can regulate the expression of MDR1 and ABCG2. The expression levels of ABCG2 and MDR1 are downregulated upon treatment of PC3 cells with cyclopamine (a SMO signaling element inhibitor), and targeted knockdown of ABCG2 and MDR1 expression by siRNA partially reverses chemoresistance $^{[79]}$.

\section{Targeting key signaling cascades}

Active anti-apoptotic pathways and parallel inactive proapoptotic pathways are also hot spots attracting researchers.
Monoclonal antibodies targeting Notch signaling have shown alluring prospects ${ }^{[0,81]}$. Inhibition of Notch1 can significantly reduce the $\mathrm{CD} 44^{+} \mathrm{CD} 24^{-/ \text {low }}$ subpopulation and lower the incidence of brain metastases from a breast cancer cell line ${ }^{[82]}$.

High levels of $\beta$-catenin have been described to correlate with CSC tumorigenicity in colon cancer ${ }^{[83]}$. Several pharmaceuticals are under investigation as inhibitors of Wnt signaling ${ }^{[84,85]}$. Monoclonal antibodies against the Wnt cascade have been tested with promising anti-tumor activity ${ }^{[86]}$.

Small-molecule Hedgehog antagonists have shown alluring potential to inhibit systemic metastases in mice bearing orthotopic xenografts from human pancreatic cancer cell lines. A significant reduction in the population of ALDH-positive cells (the tumor-initiating population in pancreatic cancer) has also been observed ${ }^{[87]}$. Several groups have exploited cyclopamine, a SMO signaling element inhibitor, to inhibit the hedgehog cascade, and cyclopamine has been shown to inhibit the growth, invasion and metastasis of breast, prostatic, pancreatic and brain malignancies both in vitro and in vivo ${ }^{[88-91]}$. Cyclopamine can act synergistically with gemcitabine to reduce the population of $\mathrm{ALDH}^{\text {high }}$ pancreatic $\mathrm{CSCs}^{[92]}$. Similarly, Clement et al have demonstrated that the combination of cyclopamine and temozolomide (TMZ) can also reduce the cell mass of glioma CSCs in vivo ${ }^{[33]}$.

Several groups have found that inhibiting NF-кB can greatly suppress chemoresistance, and inhibitors targeting NF- $\mathrm{kB}$ can mediate antitumor responses and enhance the sensitivity of tumor cells to anticancer drugs. Simultaneous delivery of DOX and the NF-KB inhibitor PDTC successfully overcomes multidrug resistance ${ }^{[94]}$. Ganta and Amiji have also observed enhanced cell apoptosis upon treatment with paclitaxel and curcumin, another NF-kB inhibitor ${ }^{[95]}$. Curcumin can dampen the protein levels of MDR $1^{[96]}$ and activate apoptosis pathways, hence impairing the capacity for multidrug resistance.

Ceramide, a secondary lipid messenger implicated in the regulation of cell proliferation, apoptosis and differentiation, has drawn much attention as a pro-apoptotic molecule that can activate apoptotic pathways via receptor independent mechanisms ${ }^{[97]}$. Devalapally et al have increased the level of ceramide in drug resistant cancer cells to lower the threshold for apoptotic signaling. Tamoxifen can inhibit the activity of ceramide-metabolizing enzymes and thus increase intracellular ceramide levels. Drug resistance in P-gp-overexpressing SKOV3(TR) cells is significantly suppressed upon simultaneous delivery of paclitaxel and tamoxifen ${ }^{[97]}$.

In addition, IL- 4 can protect the tumorigenic CD $133^{+}$CSCs in human colon carcinoma from apoptosis. Thus, an antiIL-4 antibody or IL-4Ra antagonist can cause CSCs to become apoptotic and markedly sensitize CSCs to chemotherapeutic drugs $^{[41]}$.

\section{Targeting the tumor microenvironment}

The tumor microenvironment can create a niche to nurse and protect CSCs from drug-induced apoptosis. For example, most mature B-cell malignancies are incurable. Compelling evidence has suggested that accessory stromal cells in the 
tissue microenvironments of bone marrow and secondary lymphoid organs favor disease progression by promoting malignant B-cell growth, proliferation and drug resistance ${ }^{[98]}$. One example is the interaction between stromal cell-derived factor-1 (SDF-1/CXCL12), secreted by bone marrow stromal cells, and its receptor CXCR4 ${ }^{[40]}$. CXCR4 can guide leukemia cell trafficking and homing to the bone marrow microenvironment, where secreted CXCL12 ensures that leukemia cells closely contact the marrow stromal cells, consequently activating cell growth and chemoresistance signals. CXCR4 antagonists, such as Plerixafor (AMD3100) and T14003 analogs, can damage adhesive tumor-stroma interactions and induce leukemia cell mobilization away from the bone marrow stromal microenvironment, causing the cells to become more vulnerable to cytotoxic drugs. The novel approach of targeting the CXCR4-CXCL12 axis is being explored in clinical trials for leukemia ${ }^{[40,98]}$.

Tumor angiogenesis has also been reported to be related to CSC survival and drug resistance. VEGF has been recognized to correlate with microvasculature formation and tumor growth. Targeting VEGF with bevacizumab leads to the normalization of tumor vasculature, resulting in a disruption of the CSC niche. Previous studies have demonstrated that treatment of mouse glioblastoma with bevacizumab causes a dramatic reduction in the number of glioblastoma stem cells ${ }^{[99]}$. Calabrese et al have treated mice bearing U87 glioma cell xenografts with bevacizumab and observed decreased microvasculature density and tumor growth. The authors also observed a reduction in the number of $\mathrm{CD} 133^{+} /$nestin $^{+}$tumorinitiating cells ${ }^{[100]}$. The combination of the VEGFR2 antibody DC101 and the cytotoxic agent cyclophosphamide is also more effective against C6 glioma xenografts in vivo than individual agents alone $^{[101]}$.

Weakly acidic $\mathrm{pH}$ is a well-known characteristic of the microenvironment of solid tumors. TAT peptide is an arginine-rich peptide (YGRKKRRQRRR) that currently serves to rapidly transport various types of attached molecules, such as small molecule drugs, into mammalian cells both in vitro and in vivo. Lee et al have introduced TAT to a $\mathrm{pH}$-sensitive cargo that is also conjugated to biotin. This cargo exposes biotin on its surface under slightly acidic $\mathrm{pH}$ values $(6.5<\mathrm{pH}<7.2)$. Thus, the $\mathrm{pH}$ environment together with exposed biotin can greatly increase the specificity of TAT. The latter quickly elevates the concentration of Dox in the cytosol. These processes have been reported to significantly increase the potency of Dox. This novel cargo has been evaluated in tumor xenografts of non-small cell lung cancer A549 cells, A2780/AD-resistant breast cancer MCF-7 cells and nasopharyngeal carcinoma KB cells; an obvious reduction was observed in the size of all tumors $^{[102]}$.

\section{Conclusions}

In summary, compelling evidence has shown that CSCs indeed exist in various malignancies and display capacities for self-renewal and differentiation that are critical for tumor initiation, progression, metastasis and recurrence. Currently, the identification and isolation of CSCs are primarily based on CSC surface markers. However, CSC markers are not universal, and CSC populations have repeatedly been refined due to the identification of new markers. Thus, to what extent will a suitable number of makers be identified to define the real population of CSCs? Would these biomarkers change during cancer progression? These questions still remain to be addressed.

Designing novel approaches to target CSCs has received much attention over the past several years. Increasing evidence has suggested that a comprehensive strategy might improve cancer treatments. For example, a nanoparticle conjugated to the following four crucial elements has been designed: 1) a molecule (ie, ligand) targeting a specific CSC; 2) a cytotoxic anticancer drug to eliminate CSCs; 3) a chemosensitizer to overcome drug resistance (such as an ABC transporter inhibitor); and 4) an imaging agent to facilitate tumor diagnostics. Such a combination would exert the anti-tumor effect more specifically and powerfully with fewer side-effects. Furthermore, this approach would enable accurate identification of the localization of the primary tumor and its metastases. The rise of the cancer stem cell hypothesis broadens our horizons and provides a new approach to eradicate malignancies. However, the identification of strategies that exploit the unique characteristics of CSCs requires further study and the cooperation of multidisciplinary areas.

\section{Acknowledgements}

This work was supported by the National Basic Research Program (973) of China (2009CB918902), National Key Technologies Research and Development Program of China (2013ZX10004-611), Natural Science Foundation of China (30971476, 81171943), and Hundreds of Talents Program of the Chinese Academy of Sciences 2009-2013.

\section{References}

1 Reya T, Morrison SJ, Clarke MF, Weissman IL. Stem cells, cancer, and cancer stem cells. Nature 2001; 414: 105-11.

2 Bruce WR, Van Der Gaag $H$. A quantitative assay for the number of murine lymphoma cells capable of proliferation in vivo. Nature 1963; 199: 79-80.

3 Bonnet D, Dick JE. Human acute myeloid leukemia is organized as a hierarchy that originates from a primitive hematopoietic cell. Nat Med 1997; 3: 730-7.

4 Al-Hajj M, Wicha MS, Benito-Hernandez A, Morrison SJ, Clarke MF. Prospective identification of tumorigenic breast cancer cells. Proc Natl Acad Sci U S A 2003; 100: 3983-8.

5 Kim CF, Jackson EL, Woolfenden AE, Lawrence S, Babar I, Vogel S, et al. Identification of bronchioalveolar stem cells in normal lung and lung cancer. Cell 2005; 121: 823-35.

6 O'Brien CA, Pollett A, Gallinger S, Dick JE. A human colon cancer cell capable of initiating tumour growth in immunodeficient mice. Nature 2007; 445: 106-10.

7 Collins AT, Berry PA, Hyde C, Stower MJ, Maitland NJ. Prospective identification of tumorigenic prostate cancer stem cells. Cancer Res 2005; 65: 10946-51.

8 Szotek PP, Pieretti-Vanmarcke R, Masiakos PT, Dinulescu DM, Connolly D, Foster R, et al. Ovarian cancer side population defines cells with stem cell-like characteristics and Mullerian Inhibiting 
Substance responsiveness. Proc Natl Acad Sci U S A 2006; 103: 11154-9.

9 Piccirillo SGM, Reynolds BA, Zanetti N, Lamorte G, Binda E, Broggi G, et al. Bone morphogenetic proteins inhibit the tumorigenic potential of human brain tumour-initiating cells. Nature 2006; 444: 761-5.

10 Fang D, Nguyen TK, Leishear K, Finko R, Kulp AN, Hotz S, et al. A tumorigenic subpopulation with stem cell properties in melanomas. Cancer Res 2005; 65: 9328-37.

11 Tang DG. Understanding cancer stem cell heterogeneity and plasticity. Cell Res 2012; 22: 457-72.

12 Campbell LL, Polyak K. Breast tumor heterogeneity: cancer stem cells or clonal evolution? Cell Cycle 2007; 6: 2332-8.

13 Marusyk A, Polyak K. Tumor heterogeneity: causes and consequences. Biochim Biophys Acta 2010; 1805: 105-17.

14 Anderson K, Lutz C, van Delft FW, Bateman CM, Guo Y, Colman SM, et al. Genetic variegation of clonal architecture and propagating cells in leukaemia. Nature 2011; 469: 356-61.

15 Notta F, Mullighan CG, Wang JCY, Poeppl A, Doulatov S, Phillips LA, et al. Evolution of human BCR-ABL1 lymphoblastic leukaemia-initiating cells. Nature 2011; 469: 362-7.

16 Kreso A, O'Brien CA, van Galen P, Gan OI, Notta F, Brown AMK, et al. Variable clonal repopulation dynamics influence chemotherapy response in colorectal cancer. Science 2013; 339: 543-8.

17 Dalerba P, Cho RW, Clarke MF. Cancer stem cells: models and concepts. Annu Rev Med 2007; 58: 267-84.

18 Guzman ML, Jordan CT. Considerations for targeting malignant stem cells in leukemia. Cancer Control 2004; 11: 97-104.

19 Singh SK, Hawkins C, Clarke ID, Squire JA, Bayani J, Hide T, et al. Identification of human brain tumour initiating cells. Nature 2004; 432: 396-401.

20 Ginestier C, Hur MH, Charafe-Jauffret E, Monville F, Dutcher J, Brown $\mathrm{M}$, et al. ALDH1 is a marker of normal and malignant human mammary stem cells and a predictor of poor clinical outcome. Cell Stem Cell 2007; 1: 555-67.

21 Yang ZF, Ho DW, Ng MN, Lau CK, Yu WC, Ngai P, et al. Significance of $\mathrm{CD}^{+} \mathrm{O}^{+}$cancer stem cells in human liver cancer. Cancer Cell 2008; 13: 153-66.

22 Rountree CB, Senadheera S, Mato JM, Crooks GM, Lu SC. Expansion of liver cancer stem cells during aging in methionine adenosyltransferase 1A-deficient mice. Hepatology 2008; 47: 1288-97.

23 Gilbert CA, Ross AH. Cancer stem cells: cell culture, markers, and targets for new therapies. J Cell Biochem 2009; 108: 1031-8.

24 Eramo A, Lotti F, Sette G, Pilozzi E, Biffoni M, Di Virgilio A, et al. Identification and expansion of the tumorigenic lung cancer stem cell population. Cell Death Differ 2007; 15: 504-14.

25 Ho MM, Ng AV, Lam S, Hung JY. Side population in human lung cancer cell lines and tumors is enriched with stem-like cancer cells. Cancer Res 2007; 67: 4827-33.

26 Dalerba P, Dylla SJ, Park I-K, Liu R, Wang X, Cho RW, et al. Phenotypic characterization of human colorectal cancer stem cells. Proc Natl Acad Sci U S A 2007; 104: 10158-63.

27 Yeung TM, Gandhi SC, Wilding JL, Muschel R, Bodmer WF. Cancer stem cells from colorectal cancer-derived cell lines. Proc Natl Acad Sci U S A 2010; 107: 3722-7.

28 O/'Brien CA, Pollett A, Gallinger S, Dick JE. A human colon cancer cell capable of initiating tumour growth in immunodeficient mice. Nature 2007; 445: 106-10.

29 Matsui W, Huff CA, Wang Q, Malehorn MT, Barber J, Tanhehco Y, et al. Characterization of clonogenic multiple myeloma cells. Blood 2004; 103: 2332-6.

30 Matsui W, Wang Q, Barber JP, Brennan S, Smith BD, Borrello I, et al.
Clonogenic multiple myeloma progenitors, stem cell properties, and drug resistance. Cancer Res 2008; 6: 190-7.

31 Li C, Heidt DG, Dalerba P, Burant CF, Zhang L, Adsay V, et al. Identification of pancreatic cancer stem cells. Cancer Res $2007 ; 67$ : 1030-7.

32 Simeone DM. Pancreatic cancer stem cells: implications for the treatment of pancreatic cancer. Clin Cancer Res 2008; 14: 5646-8.

33 Prince ME, Sivanandan R, Kaczorowski A, Wolf GT, Kaplan MJ, Dalerba $P$, et al. Identification of a subpopulation of cells with cancer stem cell properties in head and neck squamous cell carcinoma. Proc Natl Acad Sci U S A 2007; 104: 973-8.

34 Kruger JA, Kaplan CD, Luo Y, Zhou H, Markowitz D, Xiang R, et al. Characterization of stem cell-like cancer cells in immune-competent mice. Blood 2006; 108: 3906-12.

35 Deeley RG, Westlake C, Cole SPC. Transmembrane transport of Endo- and xenobiotics by mammalian ATP-binding cassette multidrug resistance proteins. Physiol Rev 2006; 86: 849-99.

36 Roy S, Srivastava R, Shankar S. Inhibition of PI3K/AKT and MAPK/ ERK pathways causes activation of FOXO transcription factor, leading to cell cycle arrest and apoptosis in pancreatic cancer. J Mol Signal 2010; 5: 10.

37 Chen AM, Zhang M, Wei D, Stueber D, Taratula O, Minko T, et al. Co-delivery of doxorubicin and Bcl-2 siRNA by mesoporous silica nanoparticles enhances the efficacy of chemotherapy in multidrugresistant cancer cells. Small 2009; 5: 2673-7.

38 Guo G, Qiu X, Wang S, Chen Y, Rothman PB, Wang Z, et al. Oncogenic E17K mutation in the pleckstrin homology domain of AKT1 promotes v-Abl-mediated pre-B-cell transformation and survival of Pim-deficient cells. Oncogene 2010; 29: 3845-53.

39 Baud V, Karin M. Is NF-[kappa]B a good target for cancer therapy? Hopes and pitfalls. Nat Rev Drug Discov 2009; 8: 33-40.

40 Burger JA, Peled A. CXCR4 antagonists: targeting the microenvironment in leukemia and other cancers. Leukemia 2008; 23: 43-52.

41 Todaro M, Alea MP, Di Stefano AB, Cammareri P, Vermeulen L, Iovino $\mathrm{F}$, et al. Colon cancer stem cells dictate tumor growth and resist cell death by production of interleukin-4. Cell Stem Cell 2007; 1: 389402.

42 Harrison H, Farnie G, Howell SJ, Rock RE, Stylianou S, Brennan KR, et al. Regulation of breast cancer stem cell activity by signaling through the Notch4 receptor. Cancer Res 2010; 70: 709-18.

43 Murphy M, Stordal B. Erlotinib or gefitinib for the treatment of relapsed platinum pretreated non-small cell lung cancer and ovarian cancer: a systematic review. Drug Resistance Updates 2011; 14: 177-90.

44 Gutierrez A, Sanda T, Grebliunaite R, Carracedo A, Salmena L, Ahn Y, et al. High frequency of PTEN, PI3K, and AKT abnormalities in T-cell acute lymphoblastic leukemia. Blood 2009; 114: 647-50.

45 Chen JL, Limnander A, Rothman PB. Pim-1 and Pim-2 kinases are required for efficient pre-B-cell transformation by $\mathrm{v}$-Abl oncogene. Blood 2008; 111: 1677-85.

46 Pradhan A, Lambert QT, Reuther GW. Transformation of hematopoietic cells and activation of JAK2-V617F by IL-27R, a component of a heterodimeric type I cytokine receptor. Proc Natl Acad Sci U S A 2007; 104: 18502-7.

47 Qiu X, Guo G, Chen K, Kashiwada M, Druker BJ, Rothman PB, et al. A requirement for SOCS-1 and SOCS-3 phosphorylation in Bcr-Ablinduced tumorigenesis. Neoplasia 2012; 14: 547-58.

48 Grivennikov SI, Greten FR, Karin M. Immunity, inflammation, and cancer. Cell 2010; 140: 883-99.

49 Chaturvedi MM, Sung B, Yadav VR, Kannappan R, Aggarwal BB. NF[kappa]B addiction and its role in cancer: one size does not fit all. 
Oncogene 2011; 30: 1615-30.

50 Dontu G, Jackson K, McNicholas E, Kawamura M, Abdallah W, Wicha M. Role of Notch signaling in cell-fate determination of human mammary stem/progenitor cells. Breast Cancer Res 2004; 6: R605-R615.

51 Merchant AA, Matsui W. Targeting Hedgehog - a cancer stem cell pathway. Clin Cancer Res 2010; 16: 3130-40.

52 Malanchi I, Peinado H, Kassen D, Hussenet T, Metzger D, Chambon $\mathrm{P}$, et al. Cutaneous cancer stem cell maintenance is dependent on [bgr]-catenin signalling. Nature 2008; 452: 650-3.

53 Zeng YA, Nusse R. Wnt proteins are self-renewal factors for mammary stem cells and promote their long-term expansion in culture. Cell Stem Cell 2010; 6: 568-77.

54 Reya T, Clevers H. Wnt signalling in stem cells and cancer. Nature 2005; 434: 843-50.

55 Cho K, Wang X, Nie S, Chen Z, Shin DM. Therapeutic nanoparticles for drug Delivery in cancer. Clin Cancer Res 2008; 14: 1310-6.

56 LaBarge MA. The difficulty of targeting cancer stem cell niches. Clin Cancer Res 2010; 16: 3121-9.

57 Lacerda L, Pusztai L, Woodward WA. The role of tumor initiating cells in drug resistance of breast cancer: Implications for future therapeutic approaches. Drug Resist Updat 2010; 13: 99-108.

58 Wang Z, Li Y, Ahmad A, Azmi AS, Kong D, Banerjee S, et al. Targeting miRNAs involved in cancer stem cell and EMT regulation: an emerging concept in overcoming drug resistance. Drug Resist Updat 2010; 13: 109-18.

59 Liu J, Kopečková P, Bühler P, Wolf P, Pan H, Bauer H, et al. Biorecognition and subcellular trafficking of HPMA copolymer-anti-PSMA antibody conjugates by prostate cancer cells. Mol Pharm 2009; 6 : 959-70.

60 Curiel TJ. Immunotherapy: a useful strategy to help combat multidrug resistance. Drug Resistance Updates 2012; 15: 106-13.

61 Jin L, Hope KJ, Zhai Q, Smadja-Joffe F, Dick JE. Targeting of CD44 eradicates human acute myeloid leukemic stem cells. Nat Med 2006; 12: 1167-74.

62 Jin L, Lee EM, Ramshaw HS, Busfield SJ, Peoppl AG, Wilkinson L, et al. Monoclonal antibody-mediated targeting of CD123, IL-3 receptor $\alpha$ chain, eliminates human acute myeloid leukemic stem cells. Cell Stem Cell 2009; 5: 31-42.

63 Kikushige Y, Shima T, Takayanagi S, Urata S, Miyamoto T, Iwasaki $\mathrm{H}$, et al. TIM-3 is a promising target to selectively kill acute myeloid leukemia stem cells. Cell Stem Cell 2010; 7: 708-17.

64 Chao MP, Alizadeh AA, Tang C, Jan M, Weissman-Tsukamoto R, Zhao $\mathrm{F}$, et al. Therapeutic antibody targeting of CD47 eliminates human acute lymphoblastic leukemia. Cancer Res 2011; 71: 1374-84.

65 Alkilany AM, Thompson LB, Boulos SP, Sisco PN, Murphy CJ. Gold nanorods: Their potential for photothermal therapeutics and drug delivery, tempered by the complexity of their biological interactions. Adv Drug Deliv Rev 2012; 64: 190-9.

66 Gundlach CW 4th, Caivano A, da Graca Cabreira-Hansen M, Gahremanpour A, Brown WS, Zheng Y, et al. Synthesis and evaluation of an anti-MLC1 $\times$ anti-CD90 bispecific antibody for targeting and retaining bone-marrow-derived multipotent stromal cells in infarcted myocardium. Bioconjug Chem 2011; 22: 1706-14.

67 Lin EH, Hassan M, Li Y, Zhao H, Nooka A, Sorenson E, et al. Elevated circulating endothelial progenitor marker CD133 messenger RNA levels predict colon cancer recurrence. Cancer 2007; 110: 534-42.

68 Mehra N, Penning M, Maas J, Beerepoot LV, van Daal N, van Gils CH, et al. Progenitor marker CD133 mRNA Is elevated in peripheral blood of cancer patients with bone metastases. Clin Cancer Res 2006; 12 : 4859-66.
69 Wang CH, Chiou SH, Chou CP, Chen YC, Huang YJ, Peng CA. Photothermolysis of glioblastoma stem-like cells targeted by carbon nanotubes conjugated with CD133 monoclonal antibody. Nanomedicine 2011; 7: 69-79.

70 Paola B, Barbara O, Lorenzo F, Daniel L, Giovanni B, Giuliana P. CD133 is essential for glioblastoma stem cell maintenance. STEM CELLS 2013: n/a-n/a.

71 Broxterman HJ, Gotink KJ, Verheul HMW. Understanding the causes of multidrug resistance in cancer: a comparison of doxorubicin and sunitinib. Drug Resist Updat 2009; 12: 114-26.

72 Shapira A, Livney YD, Broxterman HJ, Assaraf YG. Nanomedicine for targeted cancer therapy: Towards the overcoming of drug resistance. Drug Resist Updat 2011; 14: 150-63.

73 Patil Y, Sadhukha T, Ma L, Panyam J. Nanoparticle-mediated simultaneous and targeted delivery of paclitaxel and tariquidar overcomes tumor drug resistance. J Control Release 2009; 136: 21-9.

74 Ritchie TK, Kwon H, Atkins WM. Conformational analysis of Human ATP-binding cassette transporter ABCB1 in lipid nanodiscs and Inhibition by the antibodies MRK16 and UIC2. J Biol Chem 2011; 286: 39489-96.

75 Tsuruo T, lida H, Tsukagoshi S, Sakurai Y. Overcoming of vincristine resistance in P388 leukemia in vivo and in vitro through enhanced cytotoxicity of vincristine and vinblastine by verapamil. Cancer Res 1981; 41: 1967-72.

76 Khdair A, Di C, Patil Y, Ma L, Dou QP, Shekhar MPV, et al. Nanoparticle-mediated combination chemotherapy and photodynamic therapy overcomes tumor drug resistance. J Control Release 2010; 141: 137-44.

77 Saeki T, Nomizu T, Toi M, Ito Y, Noguchi S, Kobayashi T, et al. Dofequidar fumarate (MS-209) in combination with cyclophosphamide, doxorubicin, and fluorouracil for patients with advanced or recurrent breast cancer. J Clin Oncol 2007; 25: 411-7.

78 Minderman H, O'Loughlin KL, Pendyala L, Baer MR. VX-710 (Biricodar) increases drug retention and enhances chemosensitivity in resistant cells overexpressing P-glycoprotein, multidrug resistance protein, and breast cancer resistance protein. Clin Cancer Res 2004; 10 : 1826-34.

79 Sims-Mourtada J, Izzo JG, Ajani J, Chao KSC. Sonic hedgehog promotes multiple drug resistance by regulation of drug transport. Oncogene 2007; 26: 5674-9.

80 Fischer M, Yen WC, Kapoun AM, Wang M, O'Young G, Lewicki J, et al. Anti-DLL4 inhibits growth and reduces tumor-initiating cell frequency in colorectal tumors with oncogenic KRAS mutations. Cancer Res 2011; 71: 1520-5.

81 Li K, Li Y, Wu W, Gordon WR, Chang DW, Lu M, et al. Modulation of notch signaling by antibodies specific for the extracellular negative regulatory region of NOTCH3. J Biol Chem 2008; 283: 8046-54.

82 McGowan PM, Simedrea C, Ribot EJ, Foster PJ, Palmieri D, Steeg PS, et al. Notch1 inhibition alters the CD44hi/CD24lo population and reduces the formation of brain metastases from breast cancer. Mol Cancer Res 2011; 9: 834-44.

83 Vermeulen L, De Sousa E Melo F, van der Heijden M, Cameron K, de Jong JH, Borovski T, et al. Wnt activity defines colon cancer stem cells and is regulated by the microenvironment. Nat Cell Biol 2010; 12: 468-76.

84 Chen B, Dodge ME, Tang W, Lu J, Ma Z, Fan CW, et al. Small molecule-mediated disruption of Wnt-dependent signaling in tissue regeneration and cancer. Nat Chem Biol 2009; 5: 100-7.

85 Fujii N, You L, Xu Z, Uematsu K, Shan J, He B, et al. An antagonist of dishevelled protein-protein interaction suppresses $\beta$-catenindependent tumor cell frowth. Cancer Res 2007; 67: 573-9. 
86 He B, Reguart N, You L, Mazieres J, Xu Z, Lee AY, et al. Blockade of Wnt-1 signaling induces apoptosis in human colorectal cancer cells containing downstream mutations. Oncogene 2005; 24: 3054-8.

87 Feldmann G, Fendrich V, McGovern K, Bedja D, Bisht S, Alvarez H, et al. An orally bioavailable small-molecule inhibitor of hedgehog signaling inhibits tumor initiation and metastasis in pancreatic cancer. Mol Cancer Ther 2008; 7: 2725-35.

88 Ramaswamy B, Lu Y, Teng KY, Nuovo G, Li X, Shapiro CL, et al. Hedgehog signaling Is a novel therapeutic target in tamoxifenresistant breast cancer abarrantly activated by PI3K/AKT pathway. Cancer Res 2012; 72: 5048-59.

89 Feldmann G, Habbe N, Dhara S, Bisht S, Alvarez H, Fendrich V, et al. Hedgehog inhibition prolongs survival in a genetically engineered mouse model of pancreatic cancer. Gut 2008; 57: 1420-30.

90 Karhadkar SS, Steven Bova G, Abdallah N, Dhara S, Gardner D, Maitra A, et al. Hedgehog signalling in prostate regeneration, neoplasia and metastasis. Nature 2004; 431: 707-12.

91 Bar EE, Chaudhry A, Lin A, Fan X, Schreck K, Matsui W, et al. Cyclopamine-mediated hedgehog pathway inhibition depletes stemlike cancer cells in glioblastoma. Stem Cells 2007; 25: 2524-33.

92 Feldmann G, Dhara S, Fendrich V, Bedja D, Beaty R, Mullendore M, et al. Blockade of hedgehog signaling inhibits pancreatic cancer invasion and metastases: a new paradigm for combination therapy in solid cancers. Cancer Res 2007; 67: 2187-96.

93 Clement V, Sanchez P, de Tribolet N, Radovanovic I, Ruiz i Altaba A. HEDGEHOG-GLI1 signaling regulates human glioma growth, cancer stem cell self-renewal, and tumorigenicity. Curr Biol 2007; 17: 16572.

94 Fan L, Li F, Zhang H, Wang Y, Cheng C, Li X, et al. Co-delivery of PDTC and doxorubicin by multifunctional micellar nanoparticles to achieve active targeted drug delivery and overcome multidrug resistance. Biomaterials 2010; 31: 5634-42.

95 Ganta S, Amiji M. Coadministration of paclitaxel and curcumin in nanoemulsion formulations to overcome multidrug resistance in tumor cells. Mol Pharm 2009; 6: 928-39.

96 Bentires-Alj M, Barbu V, Fillet M, Chariot A, Relic B, Jacobs N, et al. NF-[kappa]B transcription factor induces drug resistance through MDR1 expression in cancer cells. Oncogene 2003; 22: 90-7.

97 Devalapally H, Duan Z, Seiden MV, Amiji MM. Modulation of drug resistance in ovarian adenocarcinoma by enhancing intracellular ceramide using tamoxifen-loaded biodegradable polymeric Nanoparticles. Clin Cancer Res 2008; 14: 3193-203.

98 Konopleva M, Tabe Y, Zeng Z, Andreeff M. Therapeutic targeting of microenvironmental interactions in leukemia: mechanisms and approaches. Drug Resist Updat 2009; 12: 103-13.

99 Burkhardt JK, Hofstetter CP, Santillan A, Shin BJ, Foley CP, Ballon DJ, et al. Orthotopic glioblastoma stem-like cell xenograft model in mice to evaluate intra-arterial delivery of bevacizumab: from bedside to bench. J Clin Neurosci 2012; 19: 1568-72.

100 Calabrese C, Poppleton H, Kocak M, Hogg TL, Fuller C, Hamner B, et al. A perivascular niche for brain tumor stem cells. Cancer Cell 2007; 11: 69-82.

101 Folkins C, Man S, Xu P, Shaked Y, Hicklin DJ, Kerbel RS. Anticancer therapies combining antiangiogenic and tumor cell cytotoxic effects reduce the tumor stem - like cell fraction in glioma xenograft tumors. Cancer Res 2007; 67: 3560-4.

102 Lee ES, Gao Z, Kim D, Park K, Kwon IC, Bae YH. Super pH-sensitive multifunctional polymeric micelle for tumor pHe specific TAT exposure and multidrug resistance. J Control Release 2008; 129: 228-36.

This work is licensed under the Creative Commons Attribution-NonCommercial-No Derivative Works 3.0 Unported License. To view a copy of this license, visit http://creativecommons.org/licenses/ by-nc-nd/3.0/ 